\title{
Ultrasound
}

\section{BMUS Journal Club on Twitter: An analysis of the first} \#bmus_jc discussions

\begin{tabular}{|r|l|}
\hline Journal: & Ultrasound \\
\hline Manuscript ID & ULT-20-090.R1 \\
\hline Manuscript Type: & Original Research \\
\hline Keywords: & $\begin{array}{l}\text { Professional issues < Miscellaneous, Education < Miscellaneous, } \\
\text { Sonography < Ultrasound, Ultrasound }\end{array}$ \\
\hline \multicolumn{2}{|l}{} \\
\hline
\end{tabular}

SCHOLARONE ${ }^{m}$

Manuscripts 


\section{BMUS Journal Club on Twitter: An analysis of the first}

\section{\#bmus_jc discussions}

\section{Abstract}

Introduction

Journal clubs have evolved over recent years within healthcare to encourage continuing professional development (CPD). More recently there has been a move from face to face group meeting to virtual groups utilising social media platforms. This article aims to explore the discussions and narrative following the inaugural BMUS journal club, highlighting the key discussions and themes from the participants and to provide a narrative for the future of ultrasound CPD.

Methods

The August 2020 journal club chat was focussed on the article featured in Ultrasound; "Sonographers' level of autonomy in communication in Australian obstetric settings: Does it affect their professional identity?" by Thomas et al. Data consisting of twitter correspondence were extracted and analysed from the advanced search function on Twitter using \#BMUS_JC thread. An initial review ensured related content was included. A second review and semantic thematic analysis was then conducted on the 123 tweets.

Results

In total, seven overall themes were identified between the three sub-threads within the journal club discussions. Those participating in the Twitter discussion recognised the limitations and barriers for communicating results to patients, acknowledging that training, support and regulatory involvement is required for sonographers to change practice locally and internationally.

Conclusion

The group discussions on Twitter highlight the ongoing issues for sonographer's professional identity worldwide. Furthermore, our analysis echo other contemporary studies which indicate that twitter journal clubs act as a fruitful and dynamic source of CPD, particularly in an era where social distancing is encouraged. The outcomes of the first BMUS journal club supports the wider evidence that online journal clubs can provide a successful platform for professional discussion and debate.

\section{$\underline{\text { Article }}$}

\section{Introduction}

Journal clubs have evolved over recent years within healthcare to encourage continuing professional development and awareness of ongoing research, service development and innovation. Traditionally within medical education, this has occurred through the reading and discussion of relevant journal articles (1), where this is usually facilitated by a leading practitioner who selects a relevant article and prepares the discussion points in advance of a face to face group meeting (2). In more recent years, journal clubs have extended to social media platforms, with varying examples of multimedia participation through online forum groups, websites and conferences (3). Likewise, with the growing 
popularity of professional social media platforms such as Twitter and Linkedln, there has been a growing number of successful journal clubs utilising these platforms $(4,5)$.

Twitter is a free social media platform where users can share tweets alongside links, images and other multimedia forms (emoji/gif) to express their opinions and emotions. Content on the platform can be categorised and searchable through the use of hashtags which utilise the octothorp symbol '\#'. The advantage of using Twitter for journal clubs is that it does not limit the geographical boundaries, allowing a wide range of users to participate, wherewith a character limit of 140 the communication is brief and fast-paced (5).

In August 2020 the British Medical Ultrasound Society (BMUS) organised an inaugural journal club (BMUS_JC) for both members and followers of the professional society of ultrasound on Twitter. A suitable article was chosen by the BMUS committee and journal editors for the journal club. The purpose of this article is to explore the discussions and narrative from the first BMUS Twitter Journal club, highlighting the key discussions and themes from the participants.

\section{Methods}

The BMUS_JC in August 2020 was led to discuss the Ultrasound article by Thomas et al "Sonographers' level of autonomy in communication in Australian obstetric settings: Does it affect their professional identity?" (6) The article was a qualitative study investigating sonographer practice and professionalism in Australia and the barriers to autonomy and practice. The Journal club was a one hour chat on Twitter guided by three previously published discussion topics:

1. What situations in the UK do we have that means we may not always give full results to patients?

2. Based on our own experiences in the UK, how might some of the barriers to communication/disclosure of results experienced by sonographers in Australia be overcome or reduced?

3. Is there an advantage in not giving full results to pregnant women?

The journal club event was organised through BMUS, occurring on Thursday $20^{\text {th }}$ August 2020 at 19.30 BST. Data were extracted from Twitter's site using the advanced search function to retrieve the tweets from the Journal club discussion using the \#BMUS_JC on the 20-21 ${ }^{\text {st }}$ August 2020. The tweets were reviewed manually by the first author to establish whether they were related to the discussion themes (e.g. excluding social exchanges and side conversations). Any tweets before the discussion on the $20^{\text {th }}$ were also excluded as they were mainly promoting the journal club. A manual process of reviewing each tweet was done to sort them into discussion groups for semantic thematic analysis. Following this, the analysis was reviewed with the second author.

\section{Ethical considerations}

The data reviewed were collected from Twitter which is in the public domain, and readily open for public access. Users of Twitter have to have agreed to the Terms of Service which includes consent to their profile information, and that their tweets and associated metadata (e.g. location) are publicly available (7). Also, consent for low-risk research (e.g. where users are not identified and data are presented in a collective form) is not deemed necessary as long as the objectives, methodologies and data handling practices of the study are transparent (8). Within this publication all quotes have been paraphrased to preserve anonymity of those participating. Consent was therefore not sought from participants for the presentation of the combined data, and ethical approval was not necessary. 


\section{Results}

The initial search generated 131 tweets from 16 contributors. Following searching through the responses without the \#bmus jc a total number of tweets that contributed to the discussion were divided into discussion threads and any discussions not focussed on the topics were excluded from analysis, leading to a total of 123 tweets to be included for analysis.

The final analysis describes the themes from the three different discussion threads.

\section{Discussion 1 (D1) What situations in the UK do we have that means we may not always give full results to patients? (54 tweets)}

Findings from the discussion surrounding D1, situations where sonographers do not give full results, were categorised into three main themes (Table 1). Participants began by discussing which scenarios may arise where sonographers do not give full results. Examples being cases where ultrasound has diagnostic limitations and sonographers are unable to provide full diagnosis, with the more common examples including indeterminate findings. Continuing with this theme there was discussion where the participants felt that in scenarios where a new finding is discovered on ultrasound it is important to communicate that there is a finding even if the sonographer is unable to provide the full details at that time.

Within D1 there was further discussion regarding the difficulties observed and experienced in enabling sonographers to be confident to communicate ultrasound findings. The participants recognised that this aspect of the job is difficult to learn but important to develop in trainee sonographers. Furthermore there was an overall agreement that with experience and support, a sonographer's confidence in communicating results is developed.

Lastly, there was discussion to the potential barriers for sonographers delivering results in the UK, including discouragement from peers. Participants expressed surprise that there were still areas where this culture was occurring, where it was felt that providing patients with results was a key aspect of advanced practice.

Table 1. D1 Themes derived from BMUS_JC tweet chat

\begin{tabular}{|l|l|l|}
\hline D1 Themes & Subthemes & Examples \\
\hline Limitations of ultrasound & $\begin{array}{l}\text { Full results not provided if } \\
\text { findings are not definitive }\end{array}$ & $\begin{array}{l}\text { when you see something but } \\
\text { unsure what it is ...although I } \\
\text { am still honest and say } \\
\text { something along those lines... }\end{array}$ \\
\cline { 2 - 3 } & $\begin{array}{l}\text { Providing patients with } \\
\text { enough information to inform } \\
\text { them of a new finding }\end{array}$ & $\begin{array}{l}\text { I think it's important not to } \\
\text { blindside patients and } \\
\text { communicate that something } \\
\text { has been found }\end{array}$ \\
\hline Sonographer confidence & $\begin{array}{l}\text { Sonographer confidence can } \\
\text { influence the level of } \\
\text { communication of results }\end{array}$ & $\begin{array}{l}\text { Communication issues often } \\
\text { come from a lack of } \\
\text { confidence, not having the } \\
\text { right support in place to } \\
\text { support those less confident }\end{array}$ \\
\cline { 2 - 3 } & $\begin{array}{l}\text { Recognition that } \\
\text { communicating results is a } \\
\text { difficult task }\end{array}$ & $\begin{array}{l}\text { It's been assumed that } \\
\text { communication of findings is } \\
\text { just a skill everyone has...but }\end{array}$ \\
\hline
\end{tabular}




\begin{tabular}{|l|l|l|}
\hline \multirow{2}{*}{ Barriers } & $\begin{array}{l}\text { this undermines the challenge } \\
\text { of the role }\end{array}$ \\
\cline { 2 - 3 } & $\begin{array}{l}\text { Importance of developing } \\
\text { confidence when training } \\
\text { sonographers }\end{array}$ & $\begin{array}{l}\text { Those training need time to } \\
\text { refine their skills....this needs } \\
\text { as much as the practical side of } \\
\text { the job }\end{array}$ \\
\hline & $\begin{array}{l}\text { Cultural barriers of } \\
\text { sonographers communicating } \\
\text { results }\end{array}$ & $\begin{array}{l}\text { siscouraged from saying too } \\
\text { much by others }\end{array}$ \\
\hline
\end{tabular}

Discussion 2 (D2) Based on our own experiences in the UK, how might some of the barriers to communication/disclosure of results experienced by sonographers in Australia be overcome or reduced? (54 tweets)

The conversations from the second discussion point involved reflections from sonographers in Australia and New Zealand sharing more of their experience, building from the journal article, and sonographers from the UK sharing their knowledge and advice for addressing any barriers.

Two main themes were drawn from the dialogue; approaches and barriers to developing the sonographer role to include communicating results (Table 2). Approaches included support and recognition from professional bodies in addition to demonstrating the benefits to patients for sonographers providing patients with results at the point of examination. Barriers identified the complex concerns from those from outside of the sonographer community, including protectionism from senior clinical professions and medico-legal concerns.

Table 2. D2 Themes derived from BMUS_JC tweet chat.

\begin{tabular}{|l|l|l|}
\hline D2 Themes & Subthemes & Examples \\
\hline $\begin{array}{l}\text { Approaches to } \\
\text { developing } \\
\text { sonographer } \\
\text { communicating results }\end{array}$ & $\begin{array}{l}\text { Regulatory support for } \\
\text { sonographers }\end{array}$ & $\begin{array}{l}\text { Get it formalised by working with } \\
\text { regulatory bodies }\end{array}$ \\
\cline { 2 - 3 } & $\begin{array}{l}\text { Recognition of } \\
\text { sonographers' role }\end{array}$ & $\begin{array}{l}\text { By obtaining the images you are already } \\
\text { writing the report without words... you } \\
\text { should be allowed to communicate that }\end{array}$ \\
\cline { 2 - 3 } & $\begin{array}{l}\text { Patient benefit of } \\
\text { sonographers reporting } \\
\text { findings to patients }\end{array}$ & $\begin{array}{l}\text { research strongly supports that } \\
\text { immediate reporting is in the interests of } \\
\text { patients }\end{array}$ \\
\hline $\begin{array}{l}\text { Barriers for } \\
\text { sonographers } \\
\text { communicating results }\end{array}$ & $\begin{array}{l}\text { Protectionism from senior } \\
\text { clinical professionals }\end{array}$ & $\begin{array}{l}\text { Mature radiologists not trained by } \\
\text { sonographers are more resistant to } \\
\text { development of sonographers...those } \\
\text { that have worked alongside } \\
\text { sonographers respect and understand } \\
\text { their skills }\end{array}$ \\
\cline { 2 - 3 } & $\begin{array}{l}\text { Medio-legal concerns from } \\
\text { providers }\end{array}$ & $\begin{array}{l}\text { There is a fear of medico-legal } \\
\text { implications and hierarchical } \\
\text { management controlling who does what }\end{array}$ \\
\hline
\end{tabular}

Discussion 3 (D3) Is there an advantage in not giving full results to pregnant women? (15 tweets)

Findings from this thread demonstrate that the participants did believe that despite the importance of communicating results to patients there are cases where it is beneficial not to reveal every finding to the patient, with three key examples of when this is appropriate; when findings are not clinically significant, when findings have unknown implications, and to avoid unnecessary worry for patients (Table 3). 
Furthermore there were discussions around what factors can have an influence on sonographers' decision making for providing patients with results. Multidisciplinary team (MDT) participation in both obstetric and non-obstetric ultrasound scanning was deemed important, where participants described how attending MDTs enable sonographers to understand which findings are considered to impact on a patient's care or management. Incidental findings and the knowledge of how to manage these were discussed as a complicated aspect for sonographers due to the potential impact on patient care. Lastly an understanding and openness with patients as to what their preferences are was discussed as an important factor to consider, deciding whether the knowledge might cause undue worry for them.

Table 3. D3 Themes derived from BMUS_JC tweet chat.

\begin{tabular}{|c|c|c|}
\hline D3 Themes & Subthemes & Examples \\
\hline \multirow[t]{3}{*}{$\begin{array}{l}\text { Withholding full } \\
\text { results }\end{array}$} & $\begin{array}{l}\text { Findings of no clinical } \\
\text { significance }\end{array}$ & $\begin{array}{l}\text { Only if the findings are insignificant to } \\
\text { the health and management of the } \\
\text { pregnancy }\end{array}$ \\
\hline & $\begin{array}{l}\text { When the findings are } \\
\text { indeterminate and } \\
\text { implications of findings are } \\
\text { unknown }\end{array}$ & $\begin{array}{l}\text { If findings may have variable outcomes... } \\
\text { sometimes it is best to say that you have } \\
\text { found an unexpected appearance that } \\
\text { requires an expert to discuss the } \\
\text { implications of this }\end{array}$ \\
\hline & $\begin{array}{l}\text { To avoid unnecessary } \\
\text { patient worry }\end{array}$ & $\begin{array}{l}\text { Some have said that they were relieved } \\
\text { that a fairly minor anomaly in the } \\
\text { pregnancy had not been communicated } \\
\text { because that would have been needless } \\
\text { worry }\end{array}$ \\
\hline \multirow[t]{4}{*}{$\begin{array}{l}\text { Factors that influence } \\
\text { decision making for } \\
\text { providing patients } \\
\text { with results }\end{array}$} & $\begin{array}{l}\text { MDT participation is } \\
\text { important to understand } \\
\text { what is necessary to } \\
\text { communicate results-wise. }\end{array}$ & $\begin{array}{l}\text { Potentially easier for midwife } \\
\text { sonographers who have a clinical } \\
\text { understanding of the impact to care }\end{array}$ \\
\hline & $\begin{array}{l}\text { Sonographers' experience of } \\
\text { implications of results on } \\
\text { management }\end{array}$ & $\begin{array}{l}\text { Incidental findings that won't change a } \\
\text { patients management....the } \\
\text { sonographers' experience, } \\
\text { communication skills and level of } \\
\text { confidence are key factors that help a } \\
\text { patient's experience, even when } \\
\text { something abnormal is seen }\end{array}$ \\
\hline & $\begin{array}{l}\text { Understanding how to } \\
\text { manage incidental findings }\end{array}$ & $\begin{array}{l}\text { Management of incidental findings can } \\
\text { be really difficult }\end{array}$ \\
\hline & $\begin{array}{l}\text { Considering the patient } \\
\text { preferences and } \\
\text { expectations }\end{array}$ & $\begin{array}{l}\text { What each pregnant patient wants } \\
\text { varies so much... Some want so much } \\
\text { detail and others don't...taking each } \\
\text { case individually and asking them what } \\
\text { they want is vital }\end{array}$ \\
\hline
\end{tabular}

\section{Discussion}

The findings from the first BMUS_JC demonstrated that an engaging professional, dynamic online discussion was fostered with support from the hosting organisation (BMUS). While journal clubs have traditionally been an effective way to engage healthcare professionals in CPD, the emergence of Twitter has the potential to revolutionise the format (4). COVID-19 and its rapid onset into a global pandemic has required healthcare systems to change and adapt to often extreme conditions, 
impacting the usual professional activities such as $\operatorname{CPD}(9)$, which are still vital for disseminating and interrogating the rapidly growing findings relating to the pandemic. It is evident that this unprecedented scenario has had an impact on the usual professional activities of all healthcare professionals including sonographers, limiting educational, networking and teaching face-to-face opportunities. The BMUS_JC has provided sonographers and those interested in the ultrasound community the ability to engage in critical appraisal of the evidence base, supporting dynamic worldwide shared discussion, allowing the opportunity to interact with opinion leaders. A vital resource at a time where rapid publication and review of practices are essential to moving with the fluid nature of the pandemic.

The results from this study demonstrate a professional and insightful discussion led by the pre-set discussion topics. Topics such as the communication of ultrasound findings were thoroughly interrogated and due to the global reach of the discussion forum, different experiences, ideas and practices were discussed, offering a unique insight into global practice. The Twitter threads also raised how regulatory bodies work with the sonographic workforce differently in different geographical regions (D2 point 1). In the UK sonographers report autonomously as endorsed by the Society and College of Radiographers and BMUS, who provide advice for sonographers with regard to communicating findings to patients as well as example reports (10). There is much evidence to support the benefits to patients by the immediate reporting and communicating of results by sonographers (11), however this is a debated topic both in Europe and the wider global community (12). The ability for such in-depth and professional discussions to occur and be dissected by professionals on a global scale is unique to the online journal club and may inspire further progression with a patient-focused outlook.

In a time where social distancing is required, current literature supports the benefits of opening electronic discussion forums $(1,2,4)$ where the involvement of overseas colleagues can help avoid localised echo-chambers and move discussion forums forward with new global insights.

The outcomes of the first BMUS_JC conforms to the conventional wisdom from other articles supporting online journal clubs. Current data state that online journal clubs provide a suitable, dynamic and professional platform for informed discussion and debate $(2,3,5,13)$. The advantage of this journal club was that by signposting and clarifying clear discussion points prior to the event and having a group facilitator, group discussions were focussed, with clear and balanced insights into the relevant topic. Participants in the journal club demonstrated sonographers' ability to evaluate research and apply the findings to their own clinical practice, as demonstrated through the arguments of how research supports communicating results to patients (Table 2). The outcomes from the peer-to-peer discussion within the group included a cohort of practitioners who were then able to share and apply evidence based practice examples and principles for others in the form of advice.

A notable finding from the BMUS_JC was the involvement of international participants. This feature provides insights that conventional journal clubs could not possibly achieve. The advertising and timing of the journal club was thought to have an influence on the global participation due to the time difference allowing both northern and southern hemispheres to participate, being evening for those in the UK and morning for those in Australasia. The journal club was also advertised on both the official BMUS and BMUS_JC social media accounts for 28 days prior to the event allowing adequate time for those interested to prepare. Furthermore, the Twitter discussions provided both active and 'silent' participants with a novel way to stay up to date with the latest literature and follow professional discussions in a socially distanced manner, thus allowing time to participate or review such information in an otherwise time-pressured environment. 
The informal setting and convenience of Twitter also means that connections could be and were made with international colleagues in the form of follower relationships with those within the profession (sonographers/ultrasound practitioners) and those with an interest in the journal club topic (sonographer communication). Thus conversations included views from researchers in the area and reflections from patients' perspectives. Furthermore, because the discussions remain on Twitter following the formal club times, discussions can continue long after the formal discussion.

Twitter provided a rich, free platform to invigorate and globalise CPD and the journal club. BMUS already utilises the use of social media with 2595 followers in the main twitter account and 138 followers to the BMUS_JC account, where the authors believe that with further promotion for ongoing journal clubs online can result in even more participation and discussion.

Limitations from this review include the fact that not all Tweets by participants used the hashtag, making it difficult to extract and include all the relevant discussions within the data sample. Although not surprising because of the English publication and host account being the British Medical Ultrasound Society, the chat is conducted in English only so non-English speakers did not participate, limiting the potential responses. The journal club discussions were timed for 19.30 BST which despite allowing participation from those in Australasia, may have limited participation from other geographical areas where this may have been an unsociable time for CPD activity. To potentially limit this, the journal club could consider alternating journal club timings to allow participation from those unable to commit to the inaugural event. Finally, this was an analysis of one online chat session and therefore included only a small sample of self-selected participants; further studies could elucidate greater data for a more detailed review.

\section{Conclusion}

The first BMUS twitter journal club has provided a thought-provoking discussion between a number of ultrasound practitioners regarding the ongoing issues for sonographer's professional identity worldwide, encouraging CPD participation, as well as highlighting areas for further dialogue and research going forwards. Following this review of the first event, the authors believe that pioneering \#BMUS_JC is both viable and sustainable as a source of CPD activity for ultrasound professionals. With social distancing becoming a new challenge to navigate for clinicians and academics, the BMUS journal club utilising social media (Twitter) has demonstrated how this method of group discussion for ultrasound practitioners provides the potential for impactful international communication that would not be possible otherwise.

\section{$\underline{\text { References }}$}

1. Turner, A, Rosewall, T. Implementing an innovative journal club in the workplace: a beginners' guide. J Med Imaging Radiat Sci 2011; 42: 130e6. https://doi.org/10.1016/j.jmir.2011.05.004

2. van Diggele, C, Burgess, $A$ and Mellis, $C$. Journal clubs in health professional practice. Clin Teach 2019; 16: 13-18. doi:10.1111/tct.12759

3. Aronson, JK. Journal Clubs: 2. Why and how to run them and how to publish them. BMJ Evidence-Based Medicine 2017; 22: 232-234.

4. Thangasamy, IA, Leveridge, M, Davies, BJ, Finelli, A, Stork, B, Woo, HH. International urology journal club via twitter: 12-month experience. Eur Urol 2014; 66: 112e7. https://doi.org/10.1016/j.eururo.2014.01.034

5. Bolderston, A, Watson, J, Woznitza, N, et al. Twitter journal clubs and continuing professional development: An analysis of a \#MedRadJClub tweet chat. Radiography 2018; 24: 3 https://doi.org/10.1016/j.radi.2017.09.005 
6. Thomas, S, O'Loughlin, $\mathrm{K}, \mathrm{Clarke}$, J. Sonographers' level of autonomy in communication in Australian obstetric settings: Does it affect their professional identity. Ultrasound 2020; 28 : 136

7. Twitter. Twitter terms of service. https://twitter.com/en/tos. Published 2017

8. Internet-based research (IBR). 2016 http://www.admin.ox.ac.uk/media/global/wwwadminoxacuk/localsites/curec/documents/BPG _06_Internet-Based_Research.pdf

9. Porpiglia, $F$, Checcucci, E, Amparore, $D$, et al, Slowdown of urology residents' learning curve during the COVID-19 emergency. BJU Int 2020; 125: E15-E17. doi:10.1111/bju.15076

10. [Internet]. Bmus.org. 2020 [cited 13 December 2020]. Available from: https://www.bmus.org/static/uploads/resources/Guidelines for Professional Ultrasound Pra ctice v3 OHoz76r.pdf

11. Edwards HM, Sidhu PS. Who's doing your scan? A European perspective on ultrasound services. Ultraschall Med. 2017 Oct;38(5):479-482. English. doi: 10.1055/s-0043-117449. Epub 2017 Sep 25. PMID: 28946156.)

12. Degiorgio, D, Mifsud, M, Wolstenhulme, S. Letter to the editor: Who's doing your scan? A European perspective on ultrasound services by Edwards and Sidhu. Ultraschall in der Medizin - European Journal of Ultrasound 2018; 39(01): 93 - 93 DOI: 10.1055/s-0043-125330

13. Gardhouse Al, Budd L, Yang SYC et al. \#GeriMedJC: The Twitter Complement to the Traditional-Format Geriatric Medicine Journal Club. J Am Geriatr Soc 2017; 65: 1347-1351. doi:10.1111/jgs.14920 